\title{
Correction to: Adaptive capacity of 2- to 5- month-old infants to the flow, shape, and flexibility of different teats during bottle feeding: a cross-sectional study
}

\author{
M. L. J. Lagarde ${ }^{1 *}$, N. van Alfen², S. A. F. de Groot ${ }^{1}$, A. C. H. Geurts ${ }^{1}$ and L. van den Engel-Hoek ${ }^{1}$
}

\section{Correction to: BMC Pediatrics (2019) 19:477 \\ https://doi.org/10.1186/s12887-019-1859-y}

Following the publication of the article [1], the authors noticed that Fig. 3 used is not the updated version. The correct version is shown below.

The original article has been corrected.

\begin{abstract}
Author details
'Department of Rehabilitation, Radboud University Medical Center, Donders Institute for Brain, Cognition and Behavior, Geert Grooteplein 10, 6525, GA, Nijmegen, the Netherlands. ${ }^{2}$ Department of Neurology, Radboud University Medical Center, Donders Institute for Brain, Cognition and Behavior,

Nijmegen, the Netherlands.
\end{abstract}

Published online: 30 January 2020

\section{Reference}

1. Lagarde MLJ, van Alfen N, de Groot SAF, Geurts ACH, van den Engel-Hoek L. Adaptive capacity of 2- to 5-month-old infants to the flow, shape, and flexibility of different teats during bottle feeding: a cross-sectional study. BMC Pediatr. 2019;19:477. https://doi.org/10.1186/s12887-019-1859-y.

*Correspondence: buh@usz.ch

${ }^{1}$ Department of Rehabilitation, Radboud University Medical Center, Donders Institute for Brain, Cognition and Behavior, Geert Grooteplein 10, 6525, GA, Nijmegen, the Netherlands

Full list of author information is available at the end of the article

(c) The Author(s). 2020 Open Access This article is distributed under the terms of the Creative Commons Attribution 4.0 International License (http://creativecommons.org/licenses/by/4.0/), which permits unrestricted use, distribution, and reproduction in any medium, provided you give appropriate credit to the original author(s) and the source, provide a link to the Creative Commons license, and indicate if changes were made. The Creative Commons Public Domain Dedication waiver (http://creativecommons.org/publicdomain/zero/1.0/) applies to the data made available in this article, unless otherwise stated. 


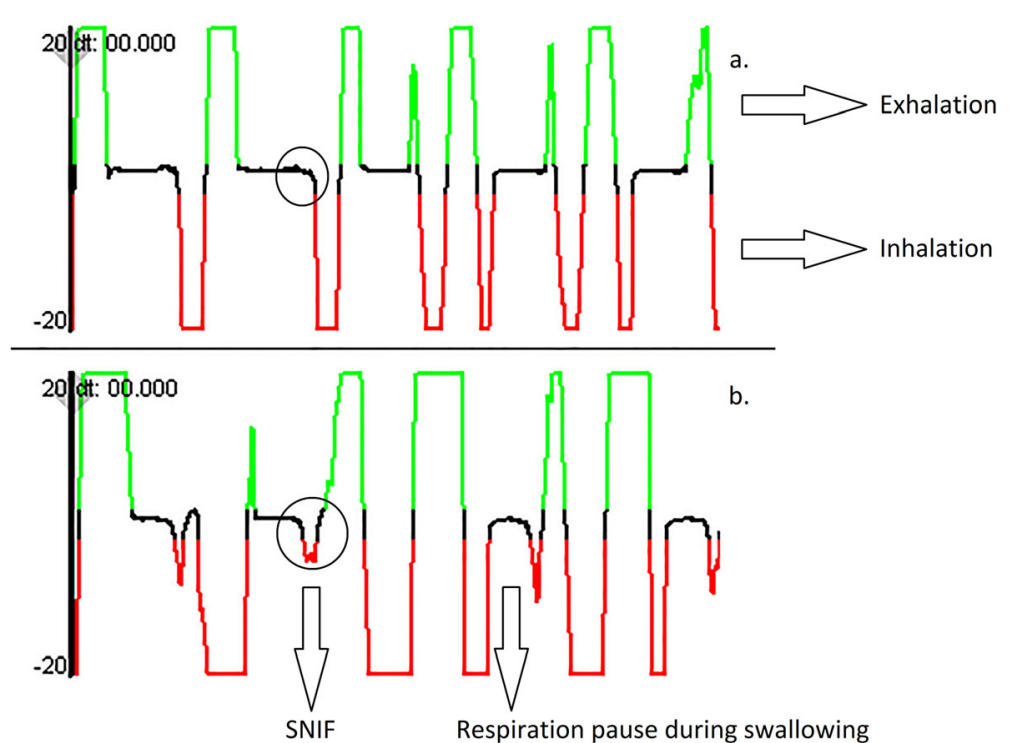

Fig. 3 Nasal airflow measurement showing $7 \mathrm{~s}$ of nutritive sucking. Nasal airflow shows (a) no swallow non-inspiratory flow (SNIF), and (b) occurrence of SNIF during swallowing 